\title{
Recombinant human growth hormone treatment in infants with chronic renal failure
}

\author{
H Maxwell, L Rees
}

\begin{abstract}
Poor growth is a particular problem for children with congenital renal disease. A one year trial of the use of recombinant human growth hormone (rhGH) in eight. infants and young children with chronic renal failure is reported here. At entry bone age was less than 2 years, mean (range) chronological age $1.9(1 \cdot 3-2 \cdot 7)$ years, and glomerular filtration rate (GFR) was $17(9-42) \mathrm{ml} / \mathrm{min} / 1.73 \mathrm{~m}^{2}$. Height standard deviation score (SDS) was $-3 \cdot 3(-4 \cdot 6$ to $-2 \cdot 0)$ and height velocity SDS was $-1 \cdot 3(-3 \cdot 1$ to $0 \cdot 7)$. One child was withdrawn when he received a renal transplant after 9.5 months. Two children required dialysis, but remained in the trial. Treatment with rhGH resulted in an increase in height SDS to $-2 \cdot 2 \mathbf{( - 4 . 2}$ to $-0.9), p=0.0002$, and height velocity SDS to $1 \cdot 1(-0.7$ to $2 \cdot 6), p=0.006$. There was no change in GFR and no serious adverse events. There was no effect on plasma lipids, calcium, phosphate, intact parathyroid hormone, or glucose. Alkaline phosphatase rose significantly. Thus rhGH improved growth in eight infants with chronic renal failure, with four children entering the normal range. (Arch Dis Child 1996; 74: 40-43)
\end{abstract}

Keywords: chronic renal failure, infants, growth, growth hormone.

Poor growth is a particular problem for children with congenital renal disease. ${ }^{1}$ Growth in the first two years of life is greater than at any other time; by the age of 2 years children have attained half of their final adult height. ${ }^{2}$ Ill health at this time results in a loss of height potential. While subsequent growth in the preschool and early school years is often normal in these children, catch up is rarely seen. ${ }^{3}$

Optimum conservative management, including provision of adequate energy, correction of electrolyte disturbance and acid-base abnormalities, and prevention of renal osteodystrophy goes some way towards improving growth, but many children remain below the normal range. ${ }^{13-7}$ Nasogastric or gastrostomy feeding to ensure adequate nutrition improves growth in some, ${ }^{38}$ but not all children. 39

Growth in the first two years of life is strongly influenced by nutrition. It is now appreciated that the influence of growth hormone is also important at this age; infants who are later diagnosed as having growth hormone deficiency are shorter and lighter than normal. ${ }^{10}$

Recombinant human growth hormone (rhGH) improves growth in older children with chronic renal failure. ${ }^{11} 12 \mathrm{We}$ present here the results of a one year study of the use of rhGH in infants and young children with chronic renal failure, who were not growing despite good conservative management.

\section{Methods}

Criteria for entry to the study were: (1) chronic renal failure with a glomerular filtration rate (GFR) of less than $50 \mathrm{ml} / \mathrm{min} / 1.73 \mathrm{~m}^{2}$; (2) a bone age of less than 2 years; (3) height less than -2 SD or a declining height standard deviation score (SDS) and no improvement in growth despite correction of fluid and electrolyte and acid-base balance, bone disease, and diet (including a trial of tube feeding when necessary); (4) absence of uncontrolled renal bone disease; (5) age less than 1 year at presentation of disease; (6) two previous height measurements in the last 6 months.

Children were excluded if there were other severe congenital abnormalities or if there had been a previous malignancy.

Growth hormone (Genotropin) (Pharmacia, Stockholm) was given as a daily subcutaneous injection $(0 \cdot 14 \mathrm{IU}(0.05 \mathrm{mg}) / \mathrm{kg} / \mathrm{d}$, equivalent to $1 \mathrm{IU} / \mathrm{kg} /$ week) in the evening for one year.

Written parental consent was obtained.

\section{PATIENTS}

Eight children (three girls, five boys) were enrolled. Mean (range) chronological age was $1.9(1 \cdot 3-2 \cdot 7)$ years. Six children had congenital structural problems, one had congenital nephrosis, and another had bilateral neonatal renal vein thrombosis. Calculated $\mathrm{GFR}^{13}$ at the start of treatment was $17(9-42) \mathrm{ml} / \mathrm{min} / 1.73 \mathrm{~m}^{2}$.

Birth weight was $3 \cdot 19(2 \cdot 24-4.50) \mathrm{kg}$ at a mean gestational age of $36 \cdot 7$ (34-41) weeks. Five of the eight infants had a birth weight within the normal range; one child was small for dates and one of the two premature infants had a weight above that expected for gestational age. Growth data for the six months preceding the trial were recorded. At the time of entry to the trial, height SDS was $-3.3(-4.6$ to $-2 \cdot 0)$. Height velocity SDS in the previous six months was $-1 \cdot 3(-3 \cdot 1$ to $0 \cdot 7)$.

\section{MEASUREMENTS}

The growth standards of Tanner et al were used to calculate the height and height velocity SDS. ${ }^{2}$ 


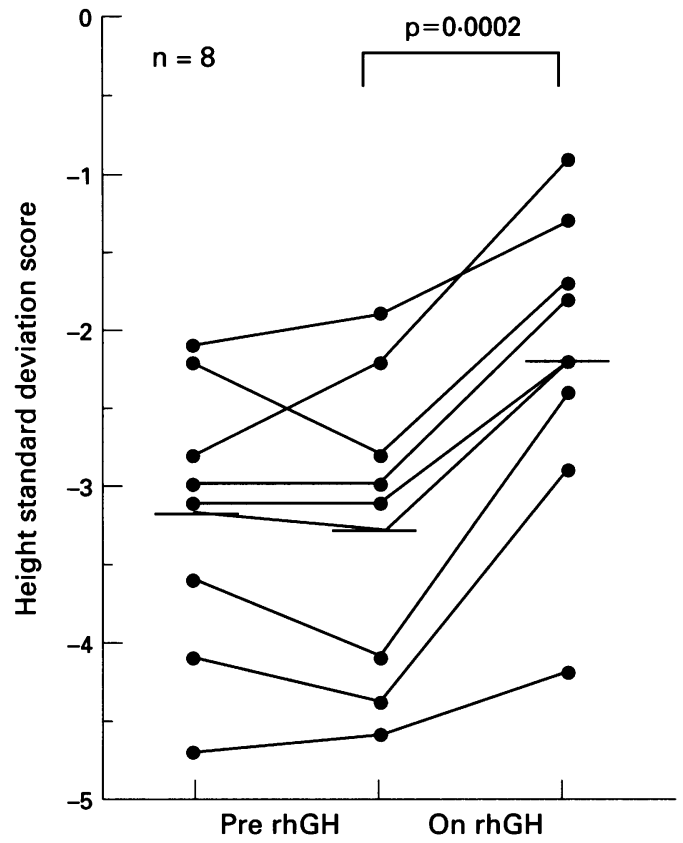

Figure 1 Height standard deviation score six months before, on day 1, and after one year of rhGH.

Children were seen three monthly, at which time blood was drawn for estimation of urea, creatinine and electrolytes, calcium, phosphate, intact parathyroid hormone (PTH), fasting glucose, insulin, cholesterol, and triglyceride. Height, weight, blood pressure, and adverse events were recorded.

Results are given as the mean (range). Statistical analysis was performed using a paired $t$ test. Analysis of variance for repeated measures was used to compare multiple measurements in the same individuals.

\section{Results}

Seven of the eight children completed one year of treatment: one child was withdrawn when he received a renal transplant after 9.5 months of rhGH. Data from this child have been included in the analysis. Two children reached end stage renal failure and were begun on peritoneal dialysis, one after four months the other after 10 months. These children completed the study and their 1 year growth data have been included.

Height SDS increased from $-3.3(-4.6$ to $-2 \cdot 0)$ to $-2 \cdot 2(-4.2$ to -0.9$) \quad(p=0.0002)$, fig 1; height velocity SDS increased from $-1 \cdot 3$ $(-2 \cdot 7$ to 0.7$)$ to $1 \cdot 1(-0.7$ to $2 \cdot 6)(\mathrm{p}=0.006)$, fig 2. Height SDS calculated six months before the study was $-3 \cdot 2(-4 \cdot 7$ to $-2 \cdot 1)$, giving a mean increase in height SDS during treatment of $1.1(0.4$ to 1.7$)$ compared to $0.08(-0.6$ to $0.6)$ in the preceding six months $(p=0.0016)$.

Response to rhGH in this group of patients was unrelated to GFR. The greatest increment in height SDS was seen in the youngest children $(r=-0.794, \mathrm{p}=0.019)$ (fig 3).

There was no change in blood pressure (table 1). Weight increased from 9.5 $(7 \cdot 5-13 \cdot 8) \mathrm{kg}$ to $10 \cdot 6(8 \cdot 3-12.9)$ at six months and $11.7(8.9-13.8)$ after one year $(p=0.008$ $v$ day 1 ). Weight, expressed as per cent of the ideal weight for height, was $98 \%(79-18)$ at the

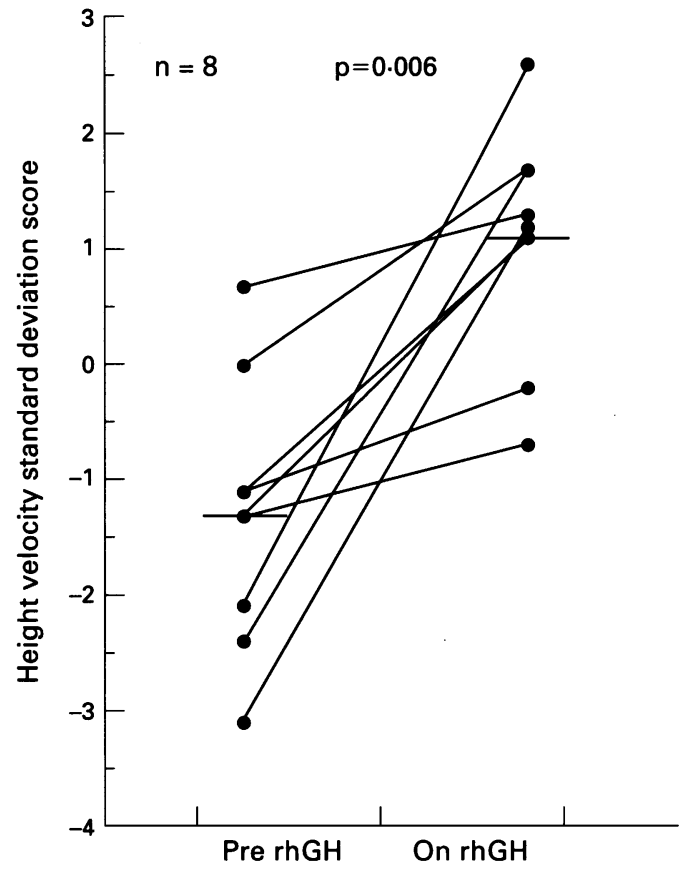

Figure 2 Height velocity standard deviation score before and during rhGH treatment.

start of the study, and $96 \%(79-127)$ after one year.

Calculated GFR $\left(\mathrm{ml} / \mathrm{min} / 1.73 \mathrm{~m}^{2}\right)$ in the children remaining on conservative management was unchanged by rhGH treatment, at $17(9-42)$ on day 1 and $17(6-34)$ after treatment. Results for creatinine, urea, and blood pressure are shown in table 1 . There were no significant changes in any of these variables. There were no consistent changes in plasma calcium, phosphate, intact PTH, triglyceride, or cholesterol (table 2). Alkaline phosphatase was raised after six months $(p=0.05)$ and remained raised at one year (table 2). Plasma glucose remained constant, but there was a trend for an increase in fasting insulin (table 2). This was not statistically significant, presumably because the sample number was small.

No serious adverse events occurred during the trial.

\section{Discussion}

In renal disease poor growth in the first two years of life can result in a significant loss of height potential. ${ }^{19}$ Growth thereafter in the preschool and early school years is often normal, so that the children grow parallel to,

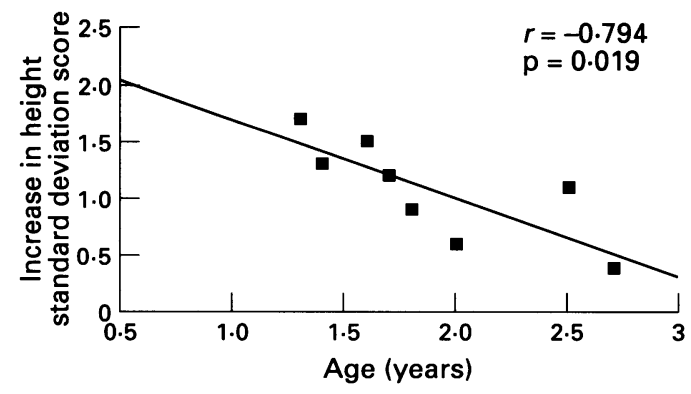

Figure 3 Increment in height standard deviation score during treatment plotted against age at start of treatment. 
Table 1 Values for urea, creatinine, and blood pressure $(B P)$ before and after recombinant human growth hormone (rhGH) treatment (mean and range)

\begin{tabular}{llcc}
\hline & Day 1 & 6 Months & After rhGH \\
\hline Creatinine (mmol/1) & $213(70-320)$ & $259(95-488)$ & $276(100-555)$ \\
Urea $(\mathrm{mmol} / \mathrm{l})$ & $13 \cdot 3(4-19 \cdot 2)$ & $11 \cdot 6(1 \cdot 7-20 \cdot 4)$ & $12 \cdot 6(1 \cdot 4-21 \cdot 9)$ \\
Systolic BP & $99(84-116)$ & $103(85-126)$ & $93(80-110)$ \\
Diastolic BP & $65(51-85)$ & $61(50-71)$ & $54(46-60)$ \\
\hline
\end{tabular}

but well below the third centile. ${ }^{34}$ Catch up growth at this time is rare. ${ }^{3}$

At entry to the trial, mean height SDS was $-3 \cdot 3$ despite a mean age of just under 2 years. A prospective study of growth in infancy in chronic renal failure reported that the major loss in height and weight SDS occurred within the first six months ${ }^{9}$; this loss can be as great as $0.6 \mathrm{SD}$ per month. ${ }^{5}$ Delay in diagnosis can therefore result in a significant loss of growth potential. Optimum conservative management, with correction of electrolytes, acid-base status, and calcium metabolism and provision of adequate nutrition improves growth in some ${ }^{3} 8$ but not all children with chronic renal failure. ${ }^{9} 12$ Improvement is more common in children who present to a paediatric nephrologist below the age of 2 years than those who present at an older age. ${ }^{3}$

Traditionally, it has been thought that growth in infancy is influenced primarily by nutrition, but recently growth hormone has been recognised as a contributing factor at this age. ${ }^{10}$ The use of energy supplements in infants with chronic renal failure, by nasogastric or gastrostomy feeding if necessary, does not consistently improve growth. ${ }^{389}$ In a placebo controlled trial, rhGH has been shown to improve growth in older prepubertal children with chronic renal failure, ${ }^{14}$ and to maintain an improved growth velocity for up to 3 to 5 years, but there is little published data of its use in infants and young children. ${ }^{15}$ The results of rhGH treatment in two boys aged less than 2 years with chronic renal failure was reported in abstract form (Linne et al, Pediatr Nephrol 1992; 6: C118). Both showed a good response to treatment.

Height SDS did not change in the six months before the trial, while it increased from $-3 \cdot 3$ to $-2 \cdot 2$ during rhGH treatment. Each child showed an improvement, with four children entering the normal range. The increment in height SDS represents good catch up growth, and interestingly the greatest improvement was seen in the youngest children (fig 3).

The dramatic changes in height velocity in the first two years of life make interpretation of growth data difficult within this age group.
Height velocity SDS has been used to allow comparison between height velocities at different ages. Ideally comparison should be with a placebo control group, but ethically this is difficult. With the small number of children involved in this study, it was decided to treat all children. Height SDS was used as the criterion for entry to the trial. Annualisation to compare height velocity at this age can be misleading because of the changing velocity, yet observing growth for one year to obtain an accurate velocity measurement will only lead to a delay in treatment.

Despite the low height SDS before treatment, mean height velocity SDS was within the normal range. This suggests that reduction in height SDS had indeed started early. Furthermore remarkable catch up growth on rhGH was seen despite relatively normal height velocity SDS values during rhGH treatment (most values were within the normal range, albeit in the upper half rather than the lower). Although this is partly an auxiological phenomenon resulting from the high rates of growth seen in infancy, it appears to be easier to achieve catch up growth at this time compared with later childhood, ${ }^{11} 1215$ a situation which is also reported following renal transplantation. ${ }^{16} 17$

Growth after infancy, in the late preschool and early school years, is often normal in chronic renal failure ${ }^{36}$; it remains to be determined whether or not children treated in infancy with $\mathrm{rhGH}$ can maintain their position within the normal range without further rhGH treatment. Perhaps a short course of treatment in infancy can achieve as much benefit as a longer course later in childhood. The benefits have to be weighed against the potential trauma of daily injections in this age group. However these children may need to remain on rhGH to maintain a height within the normal range.

There was no change in calculated GFR in the children who remained on conservative management. Patients with acromegaly have large kidneys that hyperfilter, ${ }^{18}$ and rhGH $^{2}$ increases GFR and effective renal plasma flow (ERPF) when given to subjects with normal kidneys. ${ }^{19}$ We have previously shown that one year of rhGH treatment has no effect on GFR, although there is an increase in ERPF after one week, which is no longer evident at one year. ${ }^{20}$ The long term implications of these findings are unclear. Two of the children were started on dialysis; it is not known whether rhGH treatment was implicated. The group included several children with severely reduced renal function; one child was withdrawn from the study when he received a renal transplant.

Table 2 Plasma biochemical variables before and after recombinant human growth hormone (rhGH) treatment (mean and range)

\begin{tabular}{lcccr}
\hline & Normal range & Day 1 & 6 Months & After rhGH \\
\hline Calcium (mmol/) & $(2 \cdot 12-2 \cdot 65)$ & $2 \cdot 54(2 \cdot 31-2 \cdot 74)$ & $2 \cdot 62(2 \cdot 38-2 \cdot 79)$ & $2 \cdot 54(2 \cdot 20-2 \cdot 94)$ \\
Phosphate (mmol/l) & $(1 \cdot 1-1 \cdot 8)$ & $1 \cdot 47(1 \cdot 10-1 \cdot 96)$ & $1 \cdot 51(0 \cdot 9-2 \cdot 10)$ & $1 \cdot 64(1 \cdot 30-2 \cdot 20)$ \\
PTH (ng/l) & $(15-65)$ & $140(35-436)$ & $96(22-568)$ & $75(2-570)$ \\
Alkaline phosphatase (U//) & $(150-900)$ & $432(178-870)$ & $636(265-1589)^{\star}$ & $610(270-1118)^{\star}$ \\
Fasting glucose (mmol/) & $(3 \cdot 0-6 \cdot 0)$ & $4 \cdot 8(3 \cdot 9-5 \cdot 6)$ & $4 \cdot 8(3 \cdot 5-5 \cdot 8)$ & $5 \cdot 0(4 \cdot 0-6 \cdot 3)$ \\
Fasting insulin (IU//) & & $23 \cdot 1(4 \cdot 3-68)$ & $34 \cdot 9(4 \cdot 0-75)$ & $47 \cdot 4(17 \cdot 3-92)$ \\
Cholesterol (mmol//) & $(1 \cdot 9-7 \cdot 0)$ & $5 \cdot 3(3 \cdot 3-8 \cdot 7)$ & $5 \cdot 2(3 \cdot 9-6 \cdot 4)$ & $5(3 \cdot 4-8 \cdot 2)$ \\
Triglyceride (mmol/) & $(0 \cdot 3-1 \cdot 8)$ & $2 \cdot 7(1 \cdot 7-4 \cdot 3)$ & $3 \cdot 4(2 \cdot 1-6 \cdot 5)$ & $1 \cdot 4(0 \cdot 8-2 \cdot 0)$ \\
\hline
\end{tabular}

${ }^{\star} \mathrm{p}=0.05 v$ day 1 . 
It has been much debated whether growth is related to GFR per se. It has been reported by one group ${ }^{1}$ that growth declines when the GFR falls below $25 \mathrm{ml} / \mathrm{min} / 1.73 \mathrm{~m}^{2}$, and by others that good growth can be achieved in some children even at a very low GFR values. ${ }^{56} \mathrm{We}$ were unable to find a relation between growth rate and GFR either before or after rhGH treatment, although it is noted that our group of patients is small. The two children who were started on peritoneal dialysis had the smallest increase in height SDS.

No adverse events were reported during the trial. There was no significant change in serum calcium, phosphate, or PTH, but there was an increase in alkaline phosphatase during $\mathrm{rhGH}$ treatment, as had been reported previously during accelerated growth in older children on rhGH. ${ }^{11}$ Baseline values of cholesterol and triglycerides were variable, with no consistent changes during treatment. There was a trend towards an increase in fasting insulin during rhGH, but no change in fasting glucose. The same findings have been reported previously with the use of rhGH in chronic renal failure; fasting insulin returned to baseline during the second year of treatment. ${ }^{14}$

In summary, one year of rhGH resulted in a marked improvement in height SDS in a group of infants and young children with chronic renal failure. Two children reached end stage disease and required dialysis. GFR in the remaining children was unaffected by $\mathrm{rhGH}$ treatment. There were no serious adverse events. Further study is necessary to determine the role and optimum timing of rhGH treatment in renal disease.

This study was supported by Action Research. The growth hormone was kindly provided by Pharmacia. The following paedimone was kindly provided by Pharmacia. The following paediatric nephrologists contributed to the study: Dr T J Beattie,
Glasgow; Dr M Coulthard, Dr P A Smith, Newcastle; Dr F Glasgow; Dr M Coulthard, Dr P A Smith, Newcastle; Dr F
Jewkes, Cardiff; Dr M E McGraw, Bristol; Dr C M Taylor, Birmingham.

1 Betts PR, Magrath G. Growth pattern and dietary intake of children with chronic renal insufficiency. $B M Y 1974$; i: children
2 Tanner JM, Whitehouse RH, Takaishi M. Standards from birth to maturity for height, weight, height velocity and weight velocity: British children 1965. Arch Dis Child 1966; 41: 613-35.

3 Rees L, Rigden SPA, Ward GM. Chronic renal failure and growth. Arch Dis Child 1989; 64: 573-7.

4 Polito C, Greco L, Totino SF, et al. Statural growth of children with chronic renal failure on conservative treatment. Acta Paediatr Scand 1987; 76: 97-102.

5 Rizzoni G, Basso T, Setari M. Growth in children with chronic renal failure on conservative management. Kidney Int 1984; 26: 52-8.

6 Kleinknecht C, Broyer M, Hout D, Marti-Henneberg C, Datois A-M. Growth and development of nondialyzed children with chronic renal failure. Kidney Int 1983; 24: S40-7.

7 Claris-Appiani A, Bianchi ML, Bini P, et al. Growth in young children with chronic renal failure. Pediatr Nephrol 1989; 3: 301-4

8 Strife CF, Quinlan M, Mears K, Davey ML, Clardy C. Improved growth of three uraemic children by nocturnal nasogastric feedings. Am 7 Dis Child 1986; 140: 438-43.

9 Abitol CL, Zilleruelo G, Montane B, Strauss J. Growth of uraemic infants on forced feeding regimens. Pediatr Nephrol 1993; 7: 173-7.

10 Albertsson Wikland $K$, Niklasson A, Karlberg P. Birth data for patients who later develop growth hormone deficiency: preliminary analysis of a national register. Acta Paediatr preliminary analysis of a national

11 Rees L, Rigden SPA, Ward G, Preece MA. Treatment of short stature in renal disease with recombinant human short stature in renal disease with recombinant hum
growth hormone. Arch Dis Child 1990; 65: 856-60.

12 Hokken-Koelega ACS, Stijnen T, de Muinck KeizerSchrama SMPF, et al. Placebo-controlled, double-blind, cross-over trial of growth hormone treatment in prepubertal children with chronic renal failure. Lancet 1991; 338: 585-90.

13 Schwartz GJ, Haycock G, Edelman C, Spitzer A. A simple estimate of glomerular filtration rate in children derived from body length and plasma creatinine. Pediatrics 1976; 58: 259-63.

14 Fine RN, Kohaut EC, Brown D, Perlman AJ. Growth after recombinant human growth hormone treatment in children with chronic renal failure: report of a multicentre ran1994; 124: 374-82.

15 Fine RN, Yadin O, Moulton L, Nelson PA, Boechat MI, Lippe BN. Five years experience with recombinant human growth hormone treatment of children with chronic renal failure. $¥$ Pediatr Endocrinol 1994; 7: 1-12.

16 Tejani A, Fine R, Alexander S, Harmon W, Stablein D. Factors predictive of sustained growth in children after renal transplantation. $\mathcal{F}$ Pediatr 1993; 122: 397-402.

17 Ingelfinger JR, Grupe WE, Harmon W, Fernbach SK, Levey RH. Growth acceleration following renal transplantation in children less than seven years of age. Pediatrics 1981; 68: 255-9.

18 Ikkos D, Ljunggren H, Luft R. Glomerular filtration rate and renal plasma flow in acromegaly. Acta Endocrinol 1956; 21: 226-36.

19 Hirschberg R, Rabb H, Begamo R, Kopple JD. The delayed effect of growth hormone on renal function in humans. Kidney Int 1989; 35: 865-70.

20 Maxwell H, Nair DR, Dalton RN, Rigden SPA, Rees L. Differential effects of recombinant human growth hormone on glomerular filtration rate and effective renal plasma flow. Pediatr Nephrol 1995; 9: 458-63. 